Pharmaceutical Nanotechnology

\title{
Environmentally Responsive Dual-Targeting Nanoparticles: Improving Drug Accumulation in Cancer Cells as a Way of Preventing Anticancer Drug Efflux
}

\author{
Cenk Daglioglu* \\ Department of Molecular Biology and Genetics, Faculty of Science, Izmir Institute of Technology, Urla, Izmir 35430, Turkey
}

\section{A R T I C L E I N F O}

Article history:

Received 5 June 2017

Revised 15 October 2017

Accepted 17 October 2017

\section{Keywords:}

nanoparticles

conjugation

drug resistance

targeted drug delivery

responsive delivery systems

\begin{abstract}
A B S T R A C T
Drug targeting and stimuli-responsive drug release are 2 active areas of cancer research and hold tremendous potential in the management of cancer drug resistance. In this study, I addressed this issue and focused on the synthesis and characterization of pH-responsive $\mathrm{Fe}_{3} \mathrm{O}_{4} @ \mathrm{SiO}_{2}$ (FITC)-BTN/folic acid/ DOX multifunctional nanoparticles aiming to increase drug accumulation in malignancies with both dual active targeting and endosomal drug release properties. Dye-doped silica magnetic-fluorescent composite was constructed by a simple coprecipitation of $\mathrm{Fe}^{+2} / \mathrm{Fe}^{+3}$ salts followed by sol-gel formation and dual-targeting function was obtained by conjugating folate and biotin moieties on the silica surface of nanoparticles via an esterification reaction. Doxorubicin was then successfully attached on the aminefunctionalized nanoparticles using a pH-sensitive Schiff-base formation. The physicochemical characterization of the structure was performed by dynamic light scattering, zeta potential measurement, X-ray diffraction, Fourier transform infrared spectroscopy, electron microscopy techniques, and an in vitro pHdependent release study. Cellular uptake and cytotoxicity experiments demonstrated an enhanced intracellular delivery and reduction of cancer cell viability in the cervical carcinoma HeLa cell line. Furthermore, proapoptotic studies showed that the nanoparticles increased the apoptotic rates within the same cancer cells. The preliminary cell tests confirm the potential of these multifunctional nanoparticles against the development of drug resistance in cancer cells.
\end{abstract}

() 2017 American Pharmacists Association ${ }^{\circledR}$. Published by Elsevier Inc. All rights reserved.

\section{Introduction}

Drug resistance is one of the main problems in clinical cancer treatment. The overexpression of drug efflux transporters, such as P-glycoprotein (P-gp), plays a significant role in the progression of resistance. ${ }^{1}$ To achieve targeted therapeutic concentration, higher doses or frequency of dosing are required but thus resulting in greater toxicity. ${ }^{2}$ In order to address this problem, considerable attempts have been made to exploit the drug delivery systems (DDSs) for overcoming drug resistance in cancer therapy. ${ }^{3}$ Although most DDSs conferred improved pharmacokinetics and biodistribution profiles, the poor cellular uptake and insufficient drug release inside cells remain rate-limiting steps, which lead to low intracellular drug concentration below the therapeutic window. ${ }^{4}$ Therefore, both active targeting capacity and environmentally responsive drug release character are essential features for an ideal

Conflicts of interest: The author reports no declarations of interest.

* Correspondence to: Cenk Daglioglu (Telephone: +90 232750 7319; Fax: +90232 $7507303)$.

E-mail address: cenkdaglioglu@iyte.edu.tr (C. Daglioglu).
DDS to evade drug pump efflux activity as a way of preventing drug resistance.

Among the numerous DDSs, magnetic $\left(\mathrm{Fe}_{3} \mathrm{O}_{4}\right)$ nanoparticles are promising as drug delivery vehicles for both diagnostic and therapeutic applications. ${ }^{5}$ The ease of the synthesis of magnetic nanoparticles and subsequent incorporation of various cell-specific targeting, imaging, and therapeutic functions have enabled these systems to be employed as smart nanomedicines. ${ }^{6}$ In this regard, DDSs endowed with the abilities to deal with efficient accumulation and drug release in cancer cells could lead to easier reaching of anticancer drug to the effective therapeutic concentration before the development of drug resistance.

Vitamin receptors are upregulated on a variety of human cancers due to their enhanced mitosis rates. Therefore, the overexpression of these receptors can be exploited to target vitamin-linked DDSs specifically to tumor cells. ${ }^{7}$ Considering the results reported in our previous works, the nanoparticles vectorized with biotin (vitamin B7) ${ }^{8}$ or folate (FA) (vitamin B9) ${ }^{9,10}$ were successfully penetrated into the cancer cells via receptor-mediated endocytosis. In this study, to further enhance the accumulation level of nanoparticles and to promote fast intracellular drug release 
in cancer cells in order to prevent cellular efflux, the effect of the coconjugation of 2 active targeting ligands on the surface of the nanoparticles in combination with $\mathrm{pH}$-dependent drug release property was investigated. For this reason, pH-responsive 3 successive nanoparticles: (1) $\mathrm{Fe}_{3} \mathrm{O}_{4} @ \mathrm{SiO}_{2}$ (FITC)-BTN/DOX nanoparticles containing only biotin; (2) $\mathrm{Fe}_{3} \mathrm{O}_{4} @ \mathrm{SiO}_{2}$ (FITC)-FA/DOX nanoparticles containing only folate; (3) $\mathrm{Fe}_{3} \mathrm{O}_{4} @ \mathrm{SiO}_{2}$ (FITC)-BTN/FA/ DOX nanoparticles containing both biotin and folate were fabricated to evaluate accumulation potential of the nanoparticles between single and dual targeting in inherently drug-resistant HeLa cells, which conditionally overexpress 21 of the 36 investigated transporters. ${ }^{11}$

\section{Material and Methods}

\section{Materials}

Iron (II) chloride tetrahydrate $\left(\mathrm{FeCl}_{2} 4 \mathrm{H}_{2} \mathrm{O}\right)(99 \%)$, iron (III) chloride hexahydrate $\left(\mathrm{FeCl}_{3} 6 \mathrm{H}_{2} \mathrm{O}\right)(98 \%)$, tetraethyl orthosilicate $99.9 \%$, fluorescein isothiocyanate (FITC), biotin (BTN), FA, 3aminopropyltriethoxysilane (APTES), N,N-dicyclohexyl-carbodiimide, $\mathrm{N}$-hydroxysuccinimide, glutaraldehyde $25 \%$ aqueous solution, FT-IR grade potassium bromide $\geq 99 \%$ ( $\mathrm{KBr}$ ), dimethyl sulfoxide (DMSO), Triton X-100, 3-(4,5-dimethyl-2-thialzolyl)-2,5-diphenyltetrazolium bromide (MTT), and trypsin were purchased from Sigma-Aldrich Chemicals. Doxorubicin was obtained from SABA Pharma. Oleic acid (99\%), ammonium hydroxide $25 \%$ aqueous solution, 1 -hexanol (>98\%), cyclohexane, and toluene were purchased from Fluka/Riedel-de Haën Chemicals. 7-aminoactinomycin (7-ADD) and PE-annexin-V were purchased from BD Biosciences. Dulbecco's Modified Eagle Medium growth medium, $10 \%$ fetal bovine serum, streptomycin, penicillin, and L-glutamic acid were purchased from Gibco Life Technologies. All other chemicals and reagents were of the highest purity. All the experiments were performed in deionized Milli-Q water.

\section{Cell Cultures}

HeLa (human epithelial cervical carcinoma) (93021013) cell line was kindly provided by the Biotechnology and Bioengineering Research and Application Centre, Izmir Institute of Technology, Turkey. The cancer cells were cultured in Dulbecco's Modified Eagle Medium supplemented with 10\% (v/v) fetal bovine serum, $100 \mu \mathrm{g} /$ $\mathrm{mL}$ streptomycin, $100 \mathrm{U} / \mathrm{mL}$ penicillin, and $2 \mathrm{mM}$ L-glutamic acid. The cell line was incubated in $5 \% \mathrm{CO}_{2}$ and $90 \%-100 \%$ relative humidity at $37^{\circ} \mathrm{C}$. Medium renewal was carried out 2 to 3 times per week, and cells were subcultured when they achieved 80\%-90\% confluence. The cell line was discarded after 20 generations, and new line was obtained from frozen stocks.

\section{Synthesis of Multifunctional Nanoparticles}

The parental $\mathrm{Fe}_{3} \mathrm{O}_{4} @ \mathrm{SiO}_{2}$ (FITC) nanoparticles were synthesized as described in our previous work. ${ }^{9}$ They consist of superparamagnetic iron oxide nanoparticles (as magnetic contrast agent), coated with layers of silica shells, encasing FITC within (as optical contrast agent), for imaging, biocompatibility, and molecular functionalization. To ensure preferential tumor cell uptake of the nanoparticles, the outermost layer of $\mathrm{Fe}_{3} \mathrm{O}_{4} @ \mathrm{SiO}_{2}$ (FITC) was then functionalized with BTN and/or FA molecules by silanization with BTN-APTES and/or FA-APTES conjugate. In brief, an APTES ester of BTN and/or FA (BTN-APTES/FA-APTES) was prepared by mixing biotin $(8.0 \mathrm{mg})$ and/or folate $(4.0 \mathrm{mg})$ with APTES $(2.0 \mu \mathrm{L})$ in $40 \mathrm{~mL}$ dry DMSO in the presence of $\mathrm{N}$-hydroxysuccinimide (1.1 $\mathrm{mg})$ and $\mathrm{N}, \mathrm{N}$-dicyclohexyl-carbodiimide $(4.7 \mathrm{mg})$ as the catalyst at room temperature for $2 \mathrm{~h}$. After this, a mixture of $\mathrm{Fe}_{3} \mathrm{O}_{4} @ \mathrm{SiO}_{2}$ (FITC) nanoparticles (100 mg), BTN-APTES and FAAPTES conjugate, and free APTES $(17 \mu \mathrm{L})$ in toluene $(160 \mathrm{~mL})$ was stirred at room temperature for $24 \mathrm{~h}$ to introduce BTN-APTES and FA-APTES conjugate and free APTES on the surface of silicacoated nanoparticles by hydrolysis and condensation of APTES through silanization. Final products were collected by a magnet, washed with toluene and ethanol several times to remove any unreacted reactants, and dried in vacuum oven at room temperature, overnight. In this step, besides vectorization of nanoparticles, simultaneously the surfaces were modified with free APTES to form an amine-terminated overlayer for further functionalization.

$\mathrm{Fe}_{3} \mathrm{O}_{4} @ \mathrm{SiO}_{2}$ (FITC)-BTN/DOX, $\mathrm{Fe}_{3} \mathrm{O}_{4} @ \mathrm{SiO}_{2}$ (FITC)-FA/DOX, and $\mathrm{Fe}_{3} \mathrm{O}_{4} @ \mathrm{SiO}_{2}$ (FITC)-BTN/FA/DOX nanoparticles were prepared by conjugating DOX on the surface of $\mathrm{Fe}_{3} \mathrm{O}_{4} @ \mathrm{SiO}_{2}$ (FITC)-BTN $/ \mathrm{NH}_{2}$, $\mathrm{Fe}_{3} \mathrm{O}_{4} @ \mathrm{SiO}_{2}$ (FITC)-FA/NH $\mathrm{NH}_{2}$, and $\mathrm{Fe}_{3} \mathrm{O}_{4} @ \mathrm{SiO}_{2}$ (FITC)-BTN/FA/NH nanoparticles via glutaraldehyde activation, respectively. For $\mathrm{pH}-$ responsive drug release, DOX complex was covalently linked to amine-functionalized silica surface of nanoparticles via $\mathrm{pH}$-labile Schiff-base formation from the amino sugar moiety of DOX..$^{12}$ This acid-sensitive linkage is stable at natural $\mathrm{pH}(\sim 7.4)$, but broken at mildly acidic $\mathrm{pH}(\sim 5.0)$, which allows for the release of DOX in the more acidic endosome environment ( $\mathrm{pH} 5.0$ ) versus systemic circulation $\mathrm{pH}$ (7.4). Briefly, the surface of $\mathrm{Fe}_{3} \mathrm{O}_{4} @ \mathrm{SiO}_{2}$ (FITC)-BTN/ $\mathrm{NH}_{2}, \mathrm{Fe}_{3} \mathrm{O}_{4} @ \mathrm{SiO}_{2}$ (FITC)-FA/NH $\mathrm{N}_{2}$, and $\mathrm{Fe}_{3} \mathrm{O}_{4} @ \mathrm{SiO}_{2}$ (FITC)-BTN/FA/ $\mathrm{NH}_{2}$ nanoparticles (10 mg) was activated in $20 \mathrm{~mL} 1.0 \%$ glutaraldehyde solution under vigorous mechanical stirring at room temperature for $1 \mathrm{~h}$. Then, nanoparticles were collected via centrifugation, and the unreacted glutaraldehyde was removed by extensive washing with ultrapure water. Glutaraldehydeactivated nanoparticles were subsequently incubated with DOX complex $(10 \mu \mathrm{M})$ in $20 \mathrm{~mL}$ phosphate-buffered saline (PBS) solution ( $\mathrm{pH}$ 7.4) under vigorous mechanical stirring at room temperature for $6 \mathrm{~h}$. The amount of bound DOX was calculated from the difference between the amount of DOX introduced into the coupling reaction mixture and the amount of DOX present in the washing water after immobilization by measuring DOX absorbance at $480 \mathrm{~nm}$. The resulting nanoparticles: (1) $\mathrm{Fe}_{3} \mathrm{O}_{4} @ \mathrm{SiO}_{2}(-$ FITC)-BTN/DOX; (2) $\quad \mathrm{Fe}_{3} \mathrm{O}_{4} @ \mathrm{SiO}_{2}$ (FITC)-FA/DOX; and (3) $\mathrm{Fe}_{3} \mathrm{O}_{4} @ \mathrm{SiO}_{2}$ (FITC)-BTN/FA/DOX were magnetically separated and washed with $1 \%$ DMSO in PBS several times to remove any unreacted reactants and dried under vacuum at room temperature, overnight.

\section{Structural and Physicochemical Characterization}

Dynamic light scattering (DLS) measurements were performed at $25^{\circ} \mathrm{C}$, using a Malvern Zetasizer Nano ZS compact scattering spectrometer. Average hydrodynamic diameters, size distributions, and surface charge analysis of the samples were determined using Malvern Dispersion Technology Software 7.11. Nanoparticles were suspended in ultrapure water to give optimum signal intensity. All measurements were repeated 5 times to verify the reproducibility of the results.

Powder X-ray diffraction (XRD) measurements were performed with "Philips X'Pert Pro," at room temperature by using CuK $\alpha$ radiation $(\lambda=1.5405 \AA)$ and Bragg-Brentano $\theta / 2 \theta$ configuration. The measurements were performed over the $2 \theta$ range of 20-70 .

The FTIR spectroscopy spectra of the nanoparticles were collected with a "PerkinElmer Spectrum-100" spectrophotometer in the range $450-4000 \mathrm{~cm}^{-1}$. The spectra of the dried samples were obtained by employing a $\mathrm{KBr}$ pellet. 


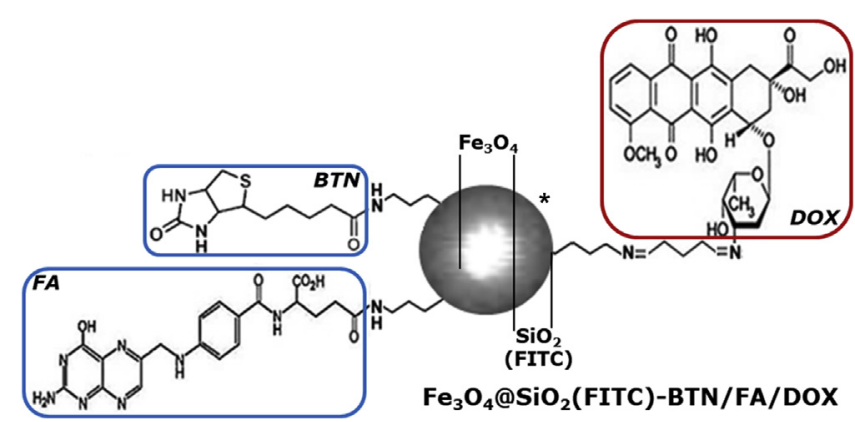

Figure 1. Schematic representation of $\mathrm{Fe}_{3} \mathrm{O}_{4} @ \mathrm{SiO}_{2}$ (FITC)-BTN/FA/DOX nanoparticles. *The core-shell structure of the particle (white core-black shell) was obtained from STEM.

Scanning electron microscopy (SEM) studies were performed with a high-resolution environmental scanning electron microscope (FEI Quanta 250 FEG) equipped with a Schottky field emission gun (FEG) for optimal spatial resolution. Before examination, the lyophilized nanoparticles were placed on a double stick tape over aluminum stubs to get a uniform layer of particles.

Scanning transmission electron microscopy (STEM) images of the nanoparticles were obtained with a "FEI Quanta 250 FEG" microscope operating with STEM detector. The nanoparticles were dispersed in water under sonication, and a drop was placed on a carbon-coated 400 mesh copper grid followed by air drying.

\section{In Vitro Release Studies}

The release of drugs from the nanoparticle formulation was examined by the dialysis bag diffusion method. The aqueous suspensions of $\mathrm{Fe}_{3} \mathrm{O}_{4} @ \mathrm{SiO}_{2}$ (FITC)-BTN/FA/DOX nanoparticles ( $1 \mathrm{mg} /$ $\mathrm{mL}$ ) were placed into dialysis bag (molecular weight cutoff 3500 $\mathrm{Da}$ ) and suspended in $25 \mathrm{~mL}$ of $1 \%$ DMSO in PBS with pH 5.0, 6.0, 7.0, or 7.4 at $37^{\circ} \mathrm{C}$ under gentle magnetic stirring, respectively. Then, 1 $\mathrm{mL}$ of the each release medium was withdrawn at predetermined time points and replaced with $1 \mathrm{~mL}$ of fresh buffer solution of relevant $\mathrm{pH}$. The amount of DOX in the withdrawn samples was determined using UV-Vis spectrometry at $480 \mathrm{~nm}$. All experimental procedures were repeated 3 times to obtain the average value. The cumulative release of DOX was calculated according to the following equation: were seeded in 12-well plates overnight to allow the adhesion of the cells before experiments. Next, the nanoparticle formulations were added to the incubation medium at a concentration of $10 \mu \mathrm{g} / \mathrm{mL}$ for 4 and $24 \mathrm{~h}$ of incubation to investigate timedependent uptake and accumulation in $5 \% \mathrm{CO}_{2}$ at $37^{\circ} \mathrm{C}$. After incubation, all cells were washed thrice with PBS and later microscopic images in the green channel, for detection of the FITC label encapsulated in nanoparticles, and in the bright-field were obtained by fluorescence microscopy. Internalization of the nanoparticles was visualized using an Olympus IX2-ILL100 fluorescence microscope equipped with an appropriate filter set. Images were acquired using a charge-coupled device camera and analyzed using Image advanced version software. For cellular uptake quantitative analysis, the cells $\left(2 \times 10^{5}\right.$ cells/well) were seeded in 6 -well plates overnight before experiments. The medium from each well was discarded, and cells were treated as described previously. The samples were trypsinized and harvested to obtain a cell suspension, which was then analyzed for the distribution of FITC fluorescence by flow cytometry.

\section{Cytotoxicity of Multifunctional Nanoparticles}

The cytotoxicity of the nanoparticle formulations was evaluated by MTT assay. HeLa cells were seeded into 96-well plates at a density of $1 \times 10^{4}$ per well and grown overnight. The cells were then incubated with increasing concentrations (0.1/0.5/1.0/10/50/100/ $200 \mu \mathrm{g} / \mathrm{mL})$ of nanoparticles and free DOX (1.0/10/100/500/1000 $\mathrm{nM}$ ) for $48 \mathrm{~h}$ at $37^{\circ} \mathrm{C}$ under $5 \% \mathrm{CO}_{2}$. Following this incubation, cells were incubated in medium containing $0.5 \mathrm{mg} / \mathrm{mL}$ of MTT for $4 \mathrm{~h}$. The medium was discarded, and the precipitated formazan violet crystals were dissolved in $150 \mu \mathrm{L}$ DMSO to solubilize the formazan. After shaking the plate for $10 \mathrm{~min}$, the absorbance of the sample was measured at $570 \mathrm{~nm}$ by multidetection microplate reader. The absorbance of dissolved formazan in the visible region correlates with the number of viable cells. The percentage of viable cells was calculated according to the following equation:

$$
\begin{aligned}
\text { Cell viability }(\%)=( & M_{\text {nanoparticles/free drugs }}-M_{\text {blank }} / \\
& \left.M_{\text {control }}-M_{\text {blank }}\right) \times 100
\end{aligned}
$$

where $M_{\text {nanoparticles/free drugs }}$ is the absorbance of the cells, growth medium, and nanoparticles or free drugs, $\mathrm{M}_{\text {control }}$ is the absorbance of the cell and growth medium, and $\mathrm{M}_{\text {blank }}$ is the absorbance of the

The cumulative release of DOX $(\%)=($ mass of released DOX/ total mass of conjugated DOX $) \times 100$

\section{Cellular Uptake Analysis}

The cellular uptake behavior of the nanoparticle formulations was investigated using fluorescence microscopy and flow cytometry. For microscopic observation, HeLa cells $\left(1 \times 10^{5}\right.$ cells/well $)$ growth medium alone. Cytotoxicity was evaluated with reference to the $\mathrm{IC}_{50}$ value that was defined as the concentration of compound causing death in $50 \%$ of cells. $\mathrm{IC}_{50}$ values were calculated by GraphPad Prism 7.0 software using sigmoidal dose-response analysis obtained in multireplicate experiments.

Table 1

\begin{tabular}{|c|c|c|c|c|}
\hline Nanoparticle Formulations & DOX Immobilization Yield (\%) & $\begin{array}{l}\text { DOX Immobilization Concentration } \\
\quad(\mu \mathrm{M} \text { per mg Nanoparticles })\end{array}$ & Size $(\mathrm{nm})$ & Zeta Potential $(\mathrm{mV})$ \\
\hline $\mathrm{Fe}_{3} \mathrm{O}_{4} @ \mathrm{SiO}_{2}(\mathrm{FITC})-\mathrm{BTN} / \mathrm{NH}_{2}$ & 91.8 & 0.92 & $37.5 \pm 6.1$ & $+7.1 \pm 2.8$ \\
\hline $\mathrm{Fe}_{3} \mathrm{O}_{4} @ \mathrm{SiO}_{2}$ (FITC)- FA/NH ${ }_{2}$ & 88.3 & 0.88 & $43.7 \pm 7.7$ & $+5.3 \pm 2.3$ \\
\hline $\mathrm{Fe}_{3} \mathrm{O}_{4} @ \mathrm{SiO}_{2}$ (FITC)- BTN/FA/NH & 79.5 & 0.79 & $47.3 \pm 8.2$ & $-1.7 \pm 1.5$ \\
\hline $\mathrm{Fe}_{3} \mathrm{O}_{4} @ \mathrm{SiO}_{2}(\mathrm{FITC})-\mathrm{BTN} / \mathrm{FA} / \mathrm{DOX}$ & - & - & $52.8 \pm 9.3$ & $-17.5 \pm 2.5$ \\
\hline
\end{tabular}

Immobilization Yields, Size, and Zeta Potential of the Nanoparticle Formulations 


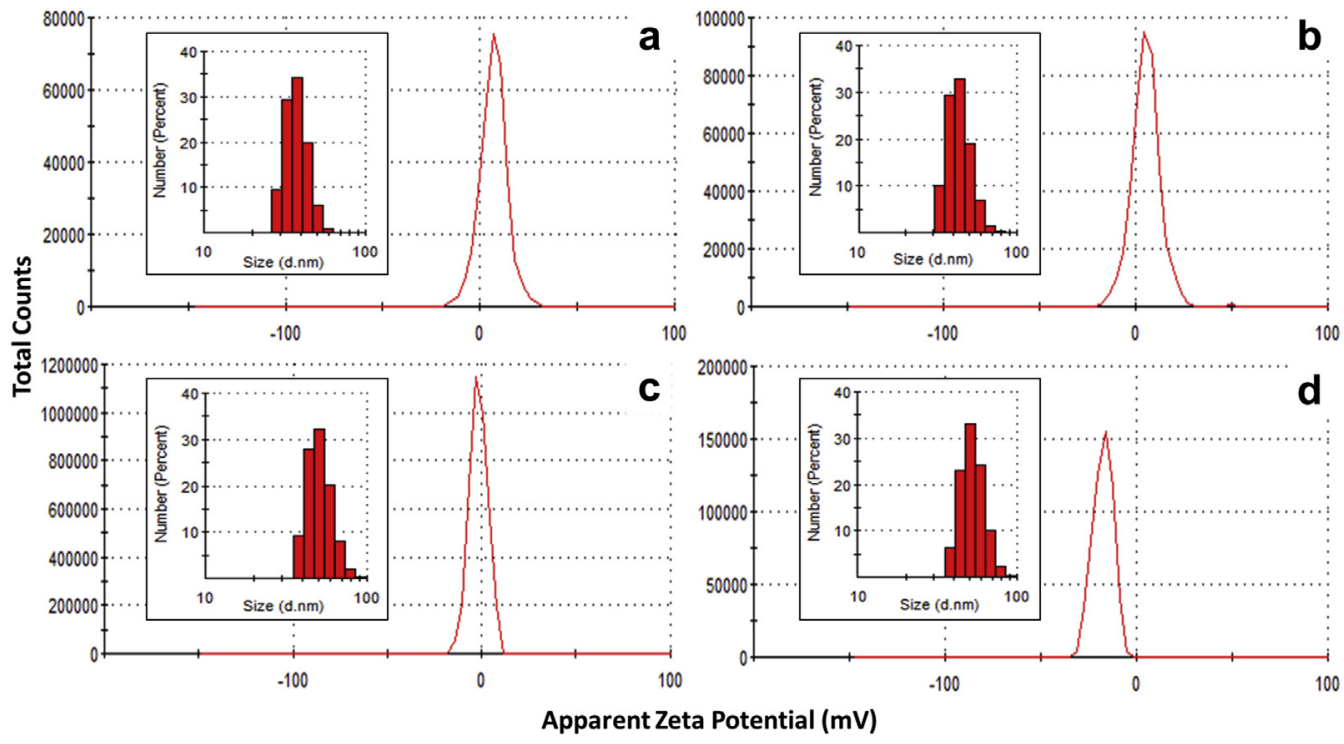

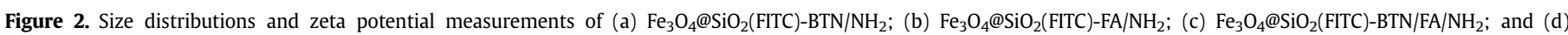
$\mathrm{Fe}_{3} \mathrm{O}_{4} @ \mathrm{SiO}_{2}$ (FITC)-BTN/FA/DOX nanoparticles obtained at $\mathrm{pH}=7.4$ using DLS.

\section{Detection of Apoptotic Cells by Flow Cytometry}

The percentage of cells undergoing apoptosis induced by the nanoparticle formulations was measured using flow cytometry with 7-ADD and PE-annexin-V double staining. HeLa cells $\left(1 \times 10^{5}\right.$ cells/well) were seeded in 6-well plates with $2 \mathrm{~mL}$ of growth medium overnight before experiments. $\mathrm{Fe}_{3} \mathrm{O}_{4} @ \mathrm{SiO}_{2}$ (FITC)-BTN/ DOX, $\mathrm{Fe}_{3} \mathrm{O}_{4} @ \mathrm{SiO}_{2}$ (FITC)-FA/DOX, or $\mathrm{Fe}_{3} \mathrm{O}_{4} @ \mathrm{SiO}_{2}$ (FITC)-BTN/FA/DOX nanoparticles were added into the incubation medium separately at $\mathrm{IC}_{50}$ concentrations and then the cells were incubated for $4 \mathrm{~h}$ in $5 \% \mathrm{CO}_{2}$ at $37{ }^{\circ} \mathrm{C}$ to allow uptake of the nanoparticles. Before analysis, the cells were carefully washed with cold PBS, digested with trypsin, and collected by centrifugation. The cells were washed twice with cold PBS, resuspended in $200 \mu \mathrm{L}$ of annexin binding buffer, and stained with $10 \mu \mathrm{L}$ of 7-ADD and PE-annexin-V.
The stained cells were first incubated for $15 \mathrm{~min}$ at room temperature in the dark, and then analyzed by flow cytometry. The untreated cells incubated with medium alone were used as the control. Unstained cells, cells stained with PE-annexin-V alone, and cells stained with 7-AAD alone were used to set up compensation and quadrants. Flow cytometric analysis was performed on a FACS (Facscanto; Becton Dickinson, San Jose, CA) by counting 10,000 events.

\section{Statistical Analysis}

All data were represented as means \pm SD. Statistical analysis was performed with the Student t-test, using Excel Software (Microsoft). A $p$ value of $\leq 0.05$ was considered statistically significant.
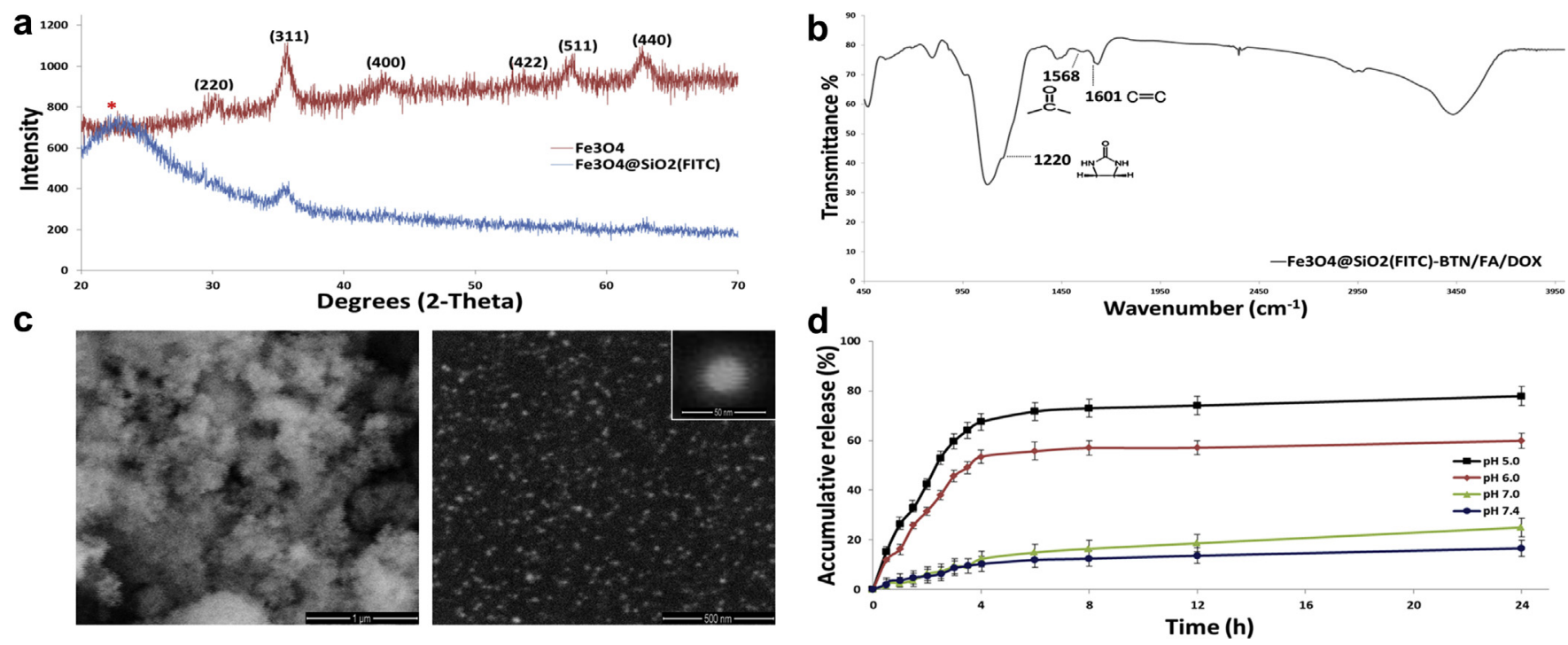

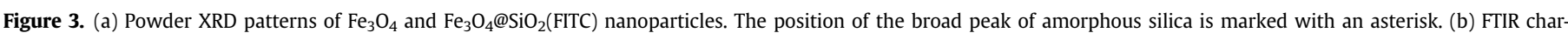

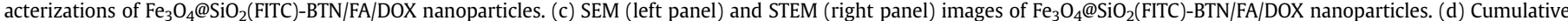
percentages of released DOX under $\mathrm{pH} 7.4,7.0,6.0$, and 5.0 over time from $\mathrm{Fe}_{3} \mathrm{O}_{4} @ \mathrm{SiO}_{2}$ (FITC)-BTN/FA/DOX nanoparticles. 
a

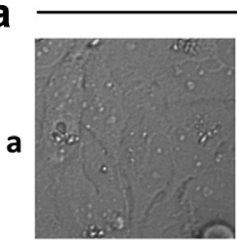

b

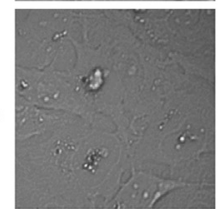

c

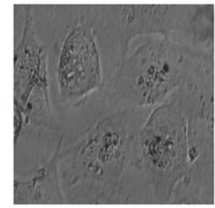

1
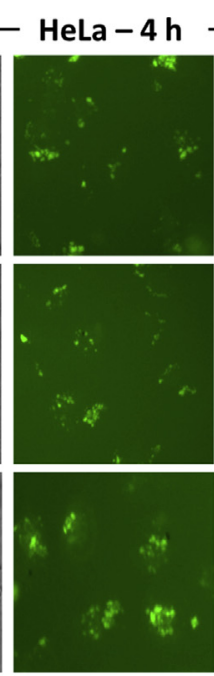

2


3
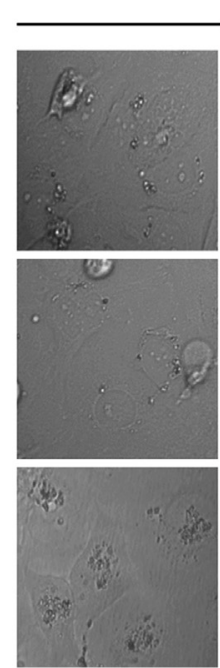

1
HeLa -24 h
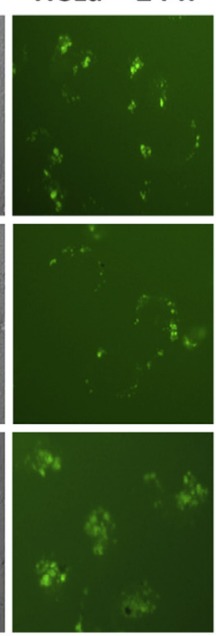

2

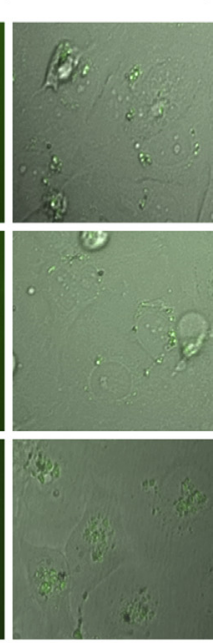

3 b
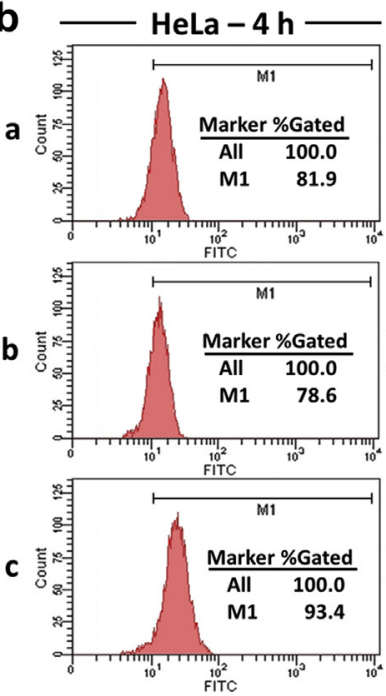
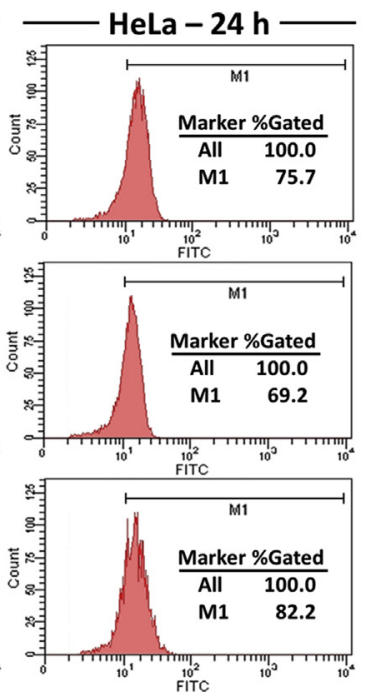

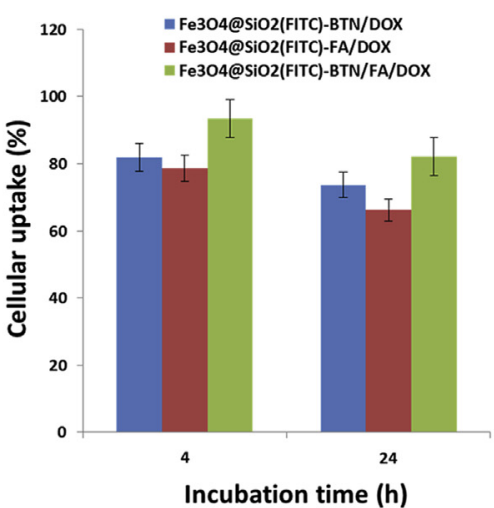

Incubation time (h)

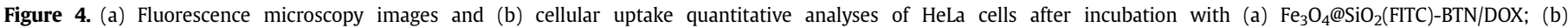

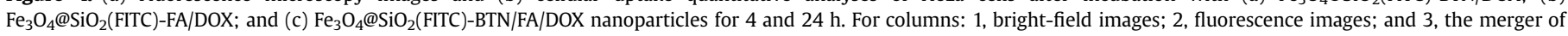
both. The histogram is a representative of $n=3$.

\section{Results and Discussion}

Synthesis and Characterization of Multifunctional Nanoparticles

In this study, The $\mathrm{Fe}_{3} \mathrm{O}_{4} @ \mathrm{SiO}_{2}$ (FITC)-BTN/FA/DOX nanoparticles consisted of silica-coated luminomagnetic nanomaterials with both fluorescent and magnetic properties, triple conjugated to BTN, FA, and DOX. To increase the cellular uptake and accumulation, nanoparticles were covectorized with BTN and FA by silanization BTN-APTES and FA-APTES conjugates on the silica surface, and simultaneously, the surfaces were modified with free APTES to form an amine-terminated overlayer for the subsequent conjugation of DOX via $\mathrm{pH}$-labile Schiffbase formation for environmentally responsive drug release (Fig. 1). The quantitative study of DOX conjugation on the silica surface showed that $0.79 \mu \mathrm{M}$ of DOX were conjugated per mg $\mathrm{Fe}_{3} \mathrm{O}_{4} @ \mathrm{SiO}_{2}$ (FITC)-BTN/FA/DOX nanoparticles, while coupling yields of $0.92 \mu \mathrm{M}$ of DOX per mg Fe $\mathrm{O}_{4} @ \mathrm{SiO}_{2}$ (FITC)-BTN/DOX and $0.88 \mu \mathrm{M}$ of DOX per $\mathrm{mg} \mathrm{Fe}_{3} \mathrm{O}_{4} @ \mathrm{SiO}_{2}$ (FITC)-FA/DOX were obtained (Table 1).

The average hydrodynamic diameter of the nanoparticle formulations were $37.5 \pm 6.1,43.7 \pm 7.7,47.3 \pm 8.2$, and $52.8 \pm 9.3 \mathrm{~nm}$ for $\quad \mathrm{Fe}_{3} \mathrm{O}_{4} @ \mathrm{SiO}_{2}$ (FITC)-BTN/NH $\mathrm{N}_{2}, \quad \mathrm{Fe}_{3} \mathrm{O}_{4} @ \mathrm{SiO}_{2}$ (FITC)-FA/NH $\mathrm{Fe}_{3} \mathrm{O}_{4} @ \mathrm{SiO}_{2}$ (FITC)-BTN/FA/NH $\mathrm{N}_{2}$, and $\mathrm{Fe}_{3} \mathrm{O}_{4} @ \mathrm{SiO}_{2}$ (FITC)-BTN/FA/ DOX nanoparticles, respectively, with narrow size distribution (Fig. 2). Particles with a diameter ranging from 10 to $100 \mathrm{~nm}$ are optimal to prevent the uptake of nanoparticles by the reticuloendothelial system, which is responsible for the clearance of nanoparticles and have the most prolonged blood circulation times. ${ }^{13}$ These long-circulating nanoparticles can efficiently accumulate in tumors cells due to their dual-targeting function and thus, deliver their therapeutic payload to cancer cells.

The stepwise conjugation of functional groups on the silica surface was monitored by measuring the surface charges at different stages of synthesis (Fig. 2 and Table 1). $\mathrm{Fe}_{3} \mathrm{O}_{4} @ \mathrm{SiO}_{2}$ (FITC)-BTN/NH and $\mathrm{Fe}_{3} \mathrm{O}_{4} @ \mathrm{SiO}_{2}$ (FITC)-FA/ $\mathrm{NH}_{2}$ nanoparticles exhibited a positive zeta potential $(\zeta)$ value of +7.1 and $+5.3(\mathrm{pH} 7.4)$, respectively, due to presence of excess positively charged amino groups, which nullify the BTN and FA charge and make the overall surface charge positive. Modification of the surface by coconjugating BTN and FA groups reverted the surface charge back to slightly negative value, for $\mathrm{Fe}_{3} \mathrm{O}_{4} @ \mathrm{SiO}_{2}$ (FITC)-BTN/FA/NH $\mathrm{NH}_{2}$ nanoparticles with average values 

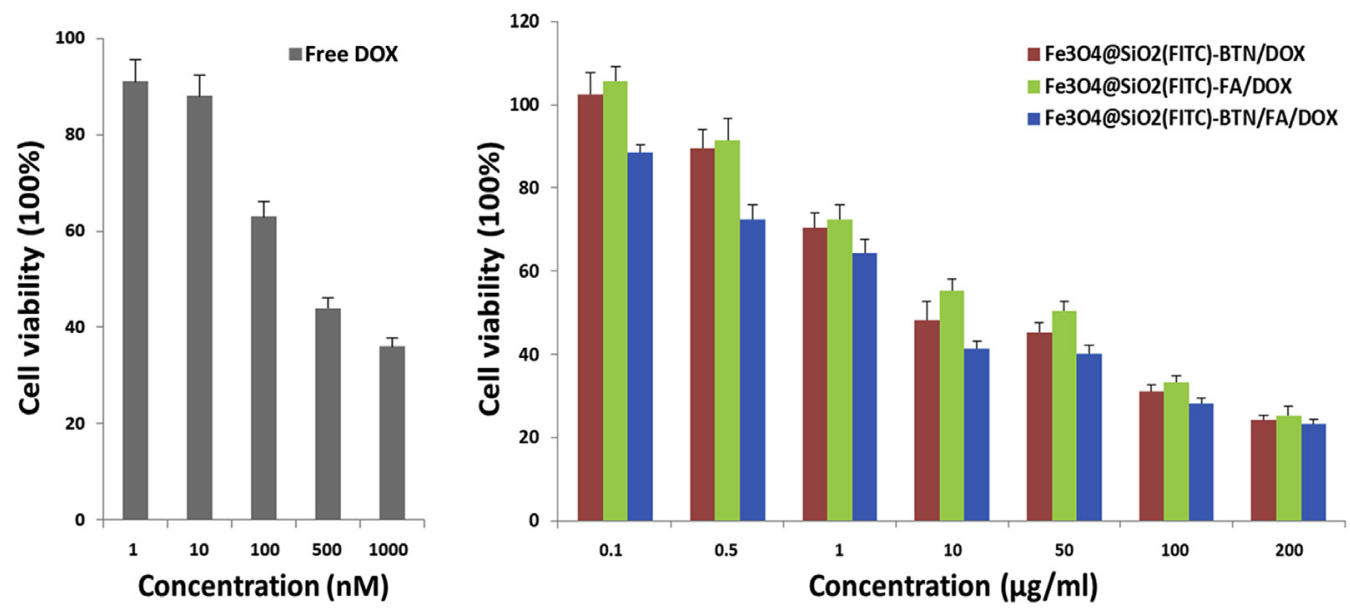

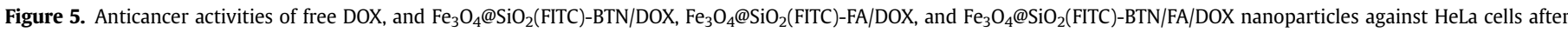

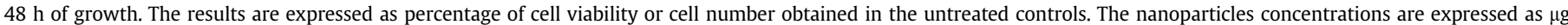
nanoparticles per $\mathrm{mL}$. Each column represents the mean \pm SD of 3 independent experiments performed in triplicate normalized to nontreated cells (taken as $100 \%$ ).

of $-1.7 \mathrm{mV}$ obtained at $\mathrm{pH}=7.4$, could be attributed to a function of the ionizability of both groups on silica surface. Further surface functionalization of the nanoparticles by conjugating DOX led to an obvious charge reversion to $-17.5 \mathrm{mV}$ values $(\mathrm{pH}=7.4)$ for $\mathrm{Fe}_{3} \mathrm{O}_{4} @ \mathrm{SiO}_{2}$ (FITC)-BTN/FA/DOX nanoparticles, attributable to a function of the high ionizability of DOX on silica surface.

The bulk crystal structure of the nanoparticles was analyzed by XRD using the Debye-Scherrer method. For $\mathrm{Fe}_{3} \mathrm{O}_{4}$ magnetic particles, XRD spectra showed the 6 characteristic peaks occurring at $2 \theta$ of 30.1 , $35.5,43.1,53.4,57.0$, and 62.6 , which are marked by their corresponding indices (220), (311), (400), (422), (511), and (440), respectively (Fig. 3a). These results were in excellent agreement with the Joint Committee on Powder Diffraction Standards file for $\mathrm{Fe}_{3} \mathrm{O}_{4}$ (card no. \#19-629). This analysis revealed that the prepared magnetic particles are pure $\mathrm{Fe}_{3} \mathrm{O}_{4}$ with a cubic spinel structure. For $\mathrm{Fe}_{3} \mathrm{O}_{4} @$ $\mathrm{SiO}_{2}$ (FITC) nanoparticles, the same 6 characteristic peaks corresponding to uncoated $\mathrm{Fe}_{3} \mathrm{O}_{4}$ were masked and a broad peak ranging from $20^{\circ}$ to $30^{\circ}$ confirmed the presence of an amorphous silica shell surrounding the $\mathrm{Fe}_{3} \mathrm{O}_{4}$ magnetic core. ${ }^{9}$ This indicated that the silica coating did not cause a phase change in the magnetic particles. Therefore, the magnetic particles could preserve their magnetic properties for further applications.

The surface conjugation of $\mathrm{Fe}_{3} \mathrm{O}_{4} @ \mathrm{SiO}_{2}$ (FITC)-BTN/FA/DOX nanoparticles with BTN, FA, and DOX were confirmed by FTIR spectroscopy. The appearance of the absorption peak at $1220 \mathrm{~cm}^{-1}$ in the FTIR spectrum confirms the existence of the biotin moieties. ${ }^{8}$ The band at $1601 \mathrm{~cm}^{-1}$ corresponding to the stretching vibrations of $\mathrm{C}=\mathrm{C}$ in the backbone of the aromatic ring present in folic acid. On the other hand, the band at $1568 \mathrm{~cm}^{-1}$ is attributed to the stretching vibration of 2 carbonyl groups of the anthracene ring of DOX, ${ }^{9}$ indicating that DOX were successfully attached to the surface of the $\mathrm{Fe}_{3} \mathrm{O}_{4} @ \mathrm{SiO}_{2}$ (FITC)-BTN/FA/NH $\mathrm{N}_{2}$ nanoparticles (Fig. 3b).

SEM and STEM images show that $\mathrm{Fe}_{3} \mathrm{O}_{4} @ \mathrm{SiO}_{2}$ (FITC)-BTN/FA/ DOX nanoparticles have core-shell morphology and nearly spherical shape with a narrow size distribution (Fig. 3c). The thickness of the shell of the nanoparticles in dry state was about $50 \mathrm{~nm}$ which is almost in accordance to those found by DLS, indicating that the coated nanoparticles are stable and well dispersed in solution without aggregation or accumulation.

\section{In Vitro pH-Stimuli Release Study}

The ability of $\mathrm{Fe}_{3} \mathrm{O}_{4} @ \mathrm{SiO}_{2}$ (FITC)-BTN/FA/DOX nanoparticles to release the conjugated DOX was tested at $\mathrm{pH} 7.4$ and 5.0, mimicking the physiological $\mathrm{pH}$ in the blood circulation and the acidic $\mathrm{pH}$ in endosome of tumor cells, and at $\mathrm{pH} 7.0$ and 6.0 to further characterize the $\mathrm{pH}$-responsive nature of the nanoparticles. As shown in Figure $3 \mathrm{~d}$, most of the drug was released from the nanoparticle formulations within a few hours at $\mathrm{pH} 5.0$, while the nanoparticles showed no more than $16 \%$ of the conjugated drug release at $\mathrm{pH} 7.4$ for $24 \mathrm{~h}$. During the first $4 \mathrm{~h}$ under $\mathrm{pH}$ 5.0, the release of DOX from the nanoparticles showed release percentages of $67 \%$, after $24 \mathrm{~h}$, the accumulated release rates of DOX increased to $77 \%$. Remarkable differences were observed between the release at $\mathrm{pH} 7.0$ and that at $\mathrm{pH}$ 6.0. As expected, drug release was accelerated at $\mathrm{pH} 6.0$ when compared with that at $\mathrm{pH} 7.0$ (Fig. 3d). Since DOX was conjugated with $\mathrm{pH}$-labile Schiff-base formation, this acid-sensitive linkage was stable at $\mathrm{pH} 7.4$ but broken at $\mathrm{pH}$ 5.0, led to the release of DOX efficiently. This meant that the nanoparticles are able to control drug release after internalization and improving the accumulation of anticancer drug at the target site to achieve the effective therapeutic concentration.

\section{Cellular Uptake}

The endocytotic uptake and accumulation of $\mathrm{Fe}_{3} \mathrm{O}_{4} @ \mathrm{SiO}_{2}$ (FITC)BTN/DOX, $\mathrm{Fe}_{3} \mathrm{O}_{4} @ \mathrm{SiO}_{2}$ (FITC)-FA/DOX, and $\mathrm{Fe}_{3} \mathrm{O}_{4} @ \mathrm{SiO}_{2}$ (FITC)-BTN/ FA/DOX nanoparticles in HeLa cells were visualized by fluorescence microscopy and flow cytometry (Figs. 4a and b). The good cellular localizations of all nanoparticle vectors, obtained by comparing the fluorescence images with the corresponding bright-field images, confirmed the persistent intracellular accumulation of the nanoparticles even after $24 \mathrm{~h}$. The fluorescence intensities in the cytoplasm revealed that the $\mathrm{Fe}_{3} \mathrm{O}_{4} @ \mathrm{SiO}_{2}$ (FITC)-BTN/FA/DOX nanoparticles ( $93.4 \%$ for $4 \mathrm{~h} ; 82.2 \%$ for $24 \mathrm{~h}$ ) with both BTN and FA

Table 2

The $\mathrm{IC}_{50}$ Values of the Nanoparticles and Free DOX in HeLa Cells When Incubated for $48 \mathrm{~h}$

\begin{tabular}{lc}
\hline Formulations & $\mathrm{IC}_{50}$ \\
\hline $\mathrm{Fe}_{3} \mathrm{O}_{4} @ \mathrm{SiO}_{2}$ (FITC)-BTN/DOX & $36.3 \pm 5.8 \mu \mathrm{g} / \mathrm{mL}$ \\
& (containing $\sim 28.7 \mathrm{nM}$ conjugated DOX) \\
$\mathrm{Fe}_{3} \mathrm{O}_{4} @ \mathrm{SiO}_{2}$ (FITC)-FA/DOX & $47.8 \pm 5.4 \mu \mathrm{g} / \mathrm{mL}$ \\
& $\quad$ (containing $\sim 37.7 \mathrm{nM}$ conjugated DOX) \\
$\mathrm{Fe}_{3} \mathrm{O}_{4} @ \mathrm{SiO}_{2}$ (FITC)-BTN/FA/DOX & $23.8 \pm 2.1 \mu \mathrm{g} / \mathrm{mL}$ \\
& (containing $\sim 18.8 \mathrm{nM}$ conjugated DOX) \\
Free DOX & $342.6 \pm 12.5 \mathrm{nM}$ \\
\hline
\end{tabular}

The values represent the mean \pm SD of 3 independent experiments. 

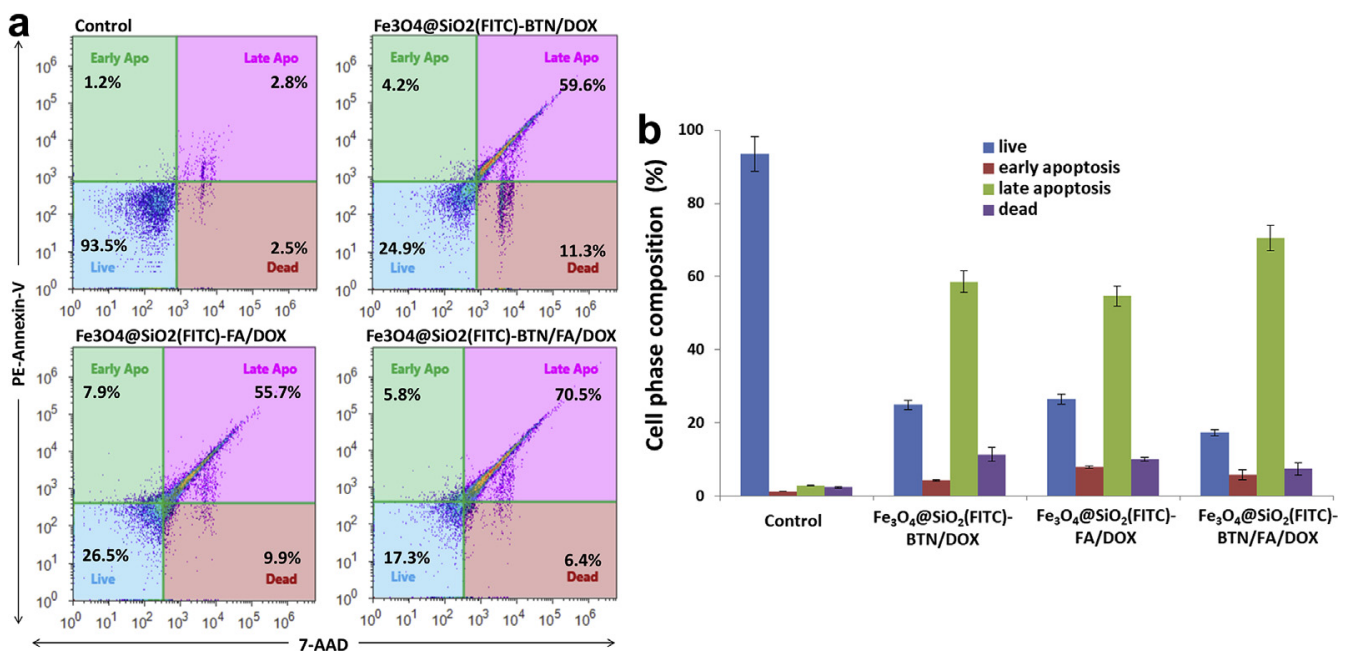

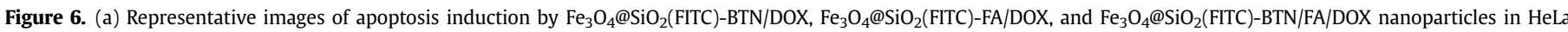

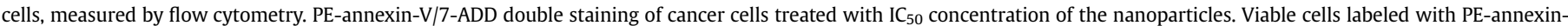

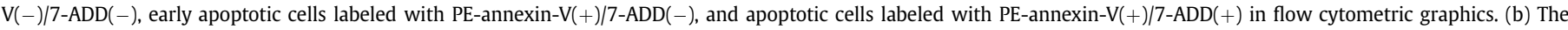

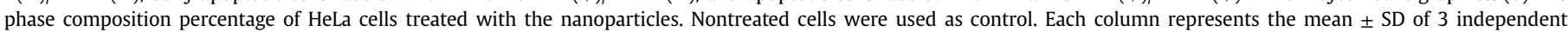
experiments performed in triplicate $(n=3)$.

targeting ligands show considerably stability and accumulation as compared to $\mathrm{Fe}_{3} \mathrm{O}_{4} @ \mathrm{SiO}_{2}$ (FITC)-BTN/DOX (81.9\% for $4 \mathrm{~h} ; 75.7 \%$ for $24 \mathrm{~h}$ ) and $\mathrm{Fe}_{3} \mathrm{O}_{4} @ \mathrm{SiO}_{2}$ (FITC)-FA/DOX (78.6\% for $4 \mathrm{~h}$; $69.2 \%$ for $24 \mathrm{~h}$ ) nanoparticles due to the dual drug uptake mechanisms that effectively evaded drug efflux pumps. Consistent with this result, it has been suggested that the cellular uptake of nanoparticles by means of receptor-mediated endocytosis leads to the greater drug accumulation due to the avoidance of the drug efflux pump mechanism. ${ }^{14}$ Therefore, dual-targeting feature could be of potential value for increasing the accumulation level of the nanoparticles, which could minimize anticancer drug expulsion, and thus improve the anticancer efficacy.

\section{Cytotoxicity of the Nanoparticle Formulations}

The cell inhibitory effect of the nanoparticle formulations was examined using MTT assay to investigate whether coconjugation of 2 active targeting ligands on the surface of the nanoparticles would be effective at inhibiting tumor cell proliferation. Cancer cells were exposed to nanoparticles with increasing concentrations of nanoparticles $(0.1-200 \mu \mathrm{g} / \mathrm{mL})$ and free DOX (1.0-1000 $\mathrm{nM})$ for $48 \mathrm{~h}$. Among all nanoparticles tested, $\mathrm{Fe}_{3} \mathrm{O}_{4} @ \mathrm{SiO}_{2}$ (FITC)-BTN/FA/DOX nanoparticles showed stronger cell inhibitory effects with approximately 1.5 - and 2.0 -fold lower $\mathrm{IC}_{50}$ value as compared to $\mathrm{Fe}_{3} \mathrm{O}_{4} @ \mathrm{SiO}_{2}$ (FITC)-BTN/DOX and $\mathrm{Fe}_{3} \mathrm{O}_{4} @ \mathrm{SiO}_{2}$ (FITC)-FA/DOX nanoparticles, respectively (Fig. 5 and Table 2). The $\mathrm{IC}_{50}$ value of $\mathrm{Fe}_{3} \mathrm{O}_{4} @ \mathrm{SiO}_{2}$ (FITC)-BTN/DOX nanoparticles was relatively lower than $\mathrm{Fe}_{3} \mathrm{O}_{4} @ \mathrm{SiO}_{2}$ (FITC)-FA/DOX nanoparticles, demonstrating that the cellular uptake capacity of BTN is higher than FA in HeLa cells. Importantly, the $\mathrm{Fe}_{3} \mathrm{O}_{4} @ \mathrm{SiO}_{2}$ (FITC)-BTN/FA/DOX nanoparticles via its dual-targeting function showed considerably cytotoxic activity at low-dose nanoparticle concentrations in comparison to singletargeting formulations which demonstrated more than $100 \%$ viabilities at similar concentrations. This increment was because of the upregulation of the adenosine triphosphate-binding cassette proteins ( $A B C$ transporters), which triggered a slight increase in the proliferation rate of cells treated with low-dose drug due to increased metabolism of the cell, ${ }^{9}$ confirming the potential of dualtargeting approach that simultaneously target multiple receptors on cancer cells resulting in robust antitumor activity due to increased drug accumulation.
For further cytotoxicity studies, the cells were exposed to increasing concentrations of free DOX to determine the $\mathrm{IC}_{50}$ value. As shown in Figure 5 and Table 2, the percentage of cell survival reduced with increasing DOX dose, however, resulted in 11.9-, 9.1-, and 18.2fold increased IC 50 values as compared to Fe3O4@SiO2(FITC)-BTN/ DOX, $\mathrm{Fe}_{3} \mathrm{O}_{4} @ \mathrm{SiO}_{2}$ (FITC)-FA/DOX, and $\mathrm{Fe}_{3} \mathrm{O}_{4} @ \mathrm{SiO}_{2}$ (FITC)-BTN/FA/ DOX nanoparticles, respectively. The $\mathrm{IC}_{50}$ values showed that $\mathrm{Fe}_{3} \mathrm{O}_{4} @ \mathrm{SiO}_{2}$ (FITC)-BTN/FA/DOX nanoparticles (containing approximately $18.8 \mathrm{nM}$ conjugated DOX) offer 5.3 times higher cytotoxic potential (lower $\mathrm{IC}_{50}$ ) than $100 \mathrm{nM}$ free DOX, representing the mean plasma concentration of doxorubicin in patients under chemotherapy, ${ }^{15}$ which would be significant in a clinical context. DOX is a common chemotherapeutic used in the treatment of a wide range of cancers, but the development of resistance by tumor cells limits its successful treatment. ${ }^{16}$ Thus, the fast endosomal accumulation and drug release functions within a single platform may able to overcome these limitations. These data corroborated that $\mathrm{Fe}_{3} \mathrm{O}_{4} @ \mathrm{SiO}_{2}$ (FITC)-BTN/FA/DOX nanoparticles with enhanced cellular uptake and drug release profiles could evade an expulsion by efflux pumps and lead to easier reaching of anticancer drug to the effective therapeutic concentration in cancer cells.

\section{Detection of Apoptotic Cells by Flow Cytometry}

To examine whether coconjugation of 2 active targeting ligands on the surface of the nanoparticles would be effective at increasing the apoptotic rates, the percentage of cells undergoing apoptosis was analyzed by flow cytometry with 7-ADD and PE-annexin-V double staining. The treatment with $\mathrm{Fe}_{3} \mathrm{O}_{4} @ \mathrm{SiO}_{2}$ (FITC)-BTN/FA/ DOX nanoparticles increased the number of apoptotic cells by nearly $12.5 \%$ as compared to the other nanoparticles, suggesting that dual-targeting function enhanced drug accumulation in cancer cells which then resulted in rapid induction of apoptosis. On the other hand, $\mathrm{Fe}_{3} \mathrm{O}_{4} @ \mathrm{SiO}_{2}$ (FITC)-BTN/DOX and $\mathrm{Fe}_{3} \mathrm{O}_{4} @ \mathrm{SiO}_{2}$ (FITC)-FA/ DOX nanoparticles showed similar apoptotic effect with total apoptotic percentages of $63.8 \%$ and $63.6 \%$, respectively (Fig. 6). These results demonstrated that $\mathrm{Fe}_{3} \mathrm{O}_{4} @ \mathrm{SiO}_{2}$ (FITC)-BTN/FA/DOX nanoparticles clearly advanced drug accumulation in cancer cells and led to an increase in the rate of total apoptosis that would be significant against resistance development. 


\section{Conclusion}

In this study, pH-responsive $\mathrm{Fe}_{3} \mathrm{O}_{4} @ \mathrm{SiO}_{2}$ (FITC)-BTN/FA/DOX multifunctional nanoparticles were synthesized to enhance nanoparticle accumulation and drug release in cancer cells as a way of preventing anticancer drug efflux activity. The structures of the nanoparticles were confirmed by different characterization techniques: DLS, XRD, FTIR, SEM, and STEM. The conjugation of DOX to the surface of nanoparticles via acid-sensitive Schiff-base led to approximately 6.5-fold improved release at $\mathrm{pH} 5$ versus $\mathrm{pH} 7.4$ in the first $4 \mathrm{~h}$. Besides its $\mathrm{pH}$-dependent drug release behavior, the coconjugation of 2 active targeting ligands on the surface of the nanoparticles led to improved intracellular nanoparticle accumulation and promoted retention of nanoparticles in the cytoplasm. The anticancer activities of the nanoparticle formulations demonstrated that the dual-targeting formulation possesses strong potential to bypass drug resistance, resulting in higher toxicity and apoptosis in cancer cells with respect to the single-targeting formulations. These results indicate that $\mathrm{Fe}_{3} \mathrm{O}_{4} @ \mathrm{SiO}_{2}$ (FITC)-BTN/FA/ DOX nanoparticles can simultaneously enhance accumulation of nanoparticles and drug release in tumor cells which may contribute to improving the therapeutic efficacy by preventing the development of drug resistance. Overall, it could be concluded that the multifunctional nanoparticle platforms with dual targeting and drug release properties might be promising as a cancer nanotherapeutic against cancer drug resistance.

\section{Acknowledgments}

The author thank Professor Mustafa M. Demir at the İzmir Institute of Technology for providing the opportunity to work in his laboratory, and Dr. Mark Thompson for proofreading the manuscript and all members of The Center for Materials Research of Izmir Institute of Technology for their technical support.

Funding: This research did not receive any specific grant from funding agencies in the public, commercial, or not-for-profit sectors.

\section{References}

1. Shukla S, Ohnuma S, Ambudkar SV. Improving cancer chemotherapy with modulators of ABC drug transporters. Curr Drug Targets. 2011;12:621-630.

2. Shapira A, Livney YD, Broxterman HJ, Assaraf YG. Nanomedicine for targeted cancer therapy: towards the overcoming of drug resistance. Drug Resist Updat 2011;14:150-163.

3. Kirtane AR, Kalscheuer SM, Panyam J. Exploiting nanotechnology to overcome tumor drug resistance: challenges and opportunities. Adv Drug Deliv Rev. 2013;65:1731-1747.

4. Su Z, Chen M, Xiao Y, et al. Ros-triggered and regenerating anticancer nanosystem: an effective strategy to subdue tumor's multidrug resistance. J Control Release. 2014;196:370-383.

5. Sun C, Lee JS, Zhang M. Magnetic nanoparticles in MR imaging and drug delivery. Adv Drug Deliv Rev. 2008;60:1252-1265.

6. Park JH, von Maltzahn G, Ruoslahti E, Bhatia SN, Sailor MJ. Micellar hybrid nanoparticles for simultaneous magneto-fluorescent imaging and drug delivery. Angew Chem Int Ed Engl. 2008;47:7284-7288.

7. Russell-Jones G, McTavish K, McEwan J, Rice J, Nowotnik D. Vitamin-mediated targeting as a potential mechanism to increase drug uptake by tumors. J Inorg Biochem. 2004;98:1625-1633.

8. Daglioglu C. Enhancing tumor cell response to multidrug resistance with $\mathrm{pH}_{-}$ sensitive quercetin and doxorubicin conjugated multifunctional nanoparticles. Colloids Surf B Biointerfaces. 2017;156:175-185.

9. Daglioglu C, Okutucu B. Synthesis and characterization of AICAR and DOX conjugated multifunctional nanoparticles as a platform for synergistic inhibition of cancer cell growth. Bioconjug Chem. 2016;27:1098-1111.

10. Daglioglu C, Okutucu B. Therapeutic effects of AICAR and DOX conjugated multifunctional nanoparticles in sensitization and elimination of cancer cells via survivin targeting. Pharm Res. 2017:34:175-184.

11. Ahlin G, Hilgendorf C, Karlsson J, Szigyarto CA, Uhlén M, Artursson P. Endogenous gene and protein expression of drug-transporting proteins in cell lines routinely used in drug discovery programs. Drug Metab Dispos. 2009;37:2275-2283.

12. Wang B, Xu C, Xie J, Yang Z, Sun S. pH controlled release of chromone from Chromone- $\mathrm{Fe}_{3} \mathrm{O}_{4}$ nanoparticles. J Am Chem Soc. 2008;130:14436-14437.

13. Laurent S, Forge D, Port M, et al. Magnetic iron oxide nanoparticles: synthesis, stabilization, vectorization, physicochemical characterizations, and biological applications. Chem Rev. 2008;108:2064-2110.

14. Patil R, Portilla-Arias J, Ding H, et al. Temozolomide delivery to tumor cells by a multifunctional nano vehicle based on poly( $\beta$-L-malic acid). Pharm Res. 2010;27:2317-2329.

15. Minotti G, Menna P, Salvatorelli E, Cairo G, Gianni L. Anthracyclines: molecular advances and pharmacologic developments in antitumor activity and cardiotoxicity. Pharmacol Rev. 2004;56:185-229.

16. Smith L, Watson MB, O'Kane SL. The analysis of doxorubicin resistance in human breast cancer cells using antibody microarrays. Mol Cancer Ther. 2006;5: 2115-2120. 